\title{
AMBER - NATURAL WEALTH OUT OF CRIMINAL PROTECTION
}

\author{
Ekaterina N. Barkhatova
}

East Siberian Institute of the Ministry of Internal Affairs of the Russian Federation, Irkutsk, Russian Federation

\section{Nikita E. Belomestnov}

Department of the Ministry of the Internal Affairs of the Russian Federation for the Trans-Baikal Territory, Chita, Russian Federation

Introduction: amber, not being, in fact, a precious stone, is of great strategic importance, having a significant impact on the formation of the state economic policy in the field of regulating the circulation of natural resources. That is why amber is included in the list of strategic resources for the purposes of art. $226^{1}$ of the Criminal Code, and often is the subject of smuggling. Unique amber formations in cases stipulated by federal law are equated to precious stones. At the same time, the criminal law protection of amber from illicit trafficking is imperfect, which determined the purpose of the work - to develop recommendations for strengthening the criminal law protection of amber and unique amber formations as a strategically important resource. Methods: the methodological basis of the study is a systematic approach, as well as a set of methods of scientific knowledge, among which should be distinguished methods of analysis and synthesis, dialectical, logical, specific sociological methods of knowledge. Conclusion: the authors have identified contradictions in federal legislation that impede the full-fledged criminal law protection of amber as a strategically important resource and in some cases a stone equivalent to a precious one. In addition, revealed contradictions concerning the subject of regulation of art. 191 of the Criminal Code of the Russian Federation as a whole. On the basis of criminological analysis, the economic importance of amber and unique amber formations, as well as the need to protect it from unlawful encroachment, is substantiated. Based on the analysis of the provisions of criminal law, as well as the Federal Law "On Precious Metals and Precious Stones", the authors formulated proposals for improving the criminal law, which provides for liability for illegal trafficking in precious metals, natural gems or pearls.

Key words: amber, unique amber formations, gems, pearls, strategic resources, economic security.

Citation. Barkhatova E.N., Belomestnov N.E. Amber - Natural Wealth out of Criminal Protection. Legal Concept, 2019, vol. 18, no. 4, pp. 174-180. (in Russian). DOI: https://doi.org/10.15688/lc.jvolsu.2019.4.24

УДК 343.37:549.091

Дата поступления статьи: 07.09.2019

ББК 67.408.122.33

Дата принятия статьи: 06.10.2019

\section{ЯНТАРЬ - ПРИРОДНОЕ БОГАТСТВО ВНЕ УГОЛОВНО-ПРАВОВОЙ ЗАЩИТЫ}

\author{
Екатерина Николаевна Бархатова \\ Восточно-Сибирский институт МВД России, г. Иркутск, Российская Федерация
}

\section{Никита Евгеньевич Беломестнов}

Управление Министерства внутренних дел Российской Федерации по Забайкальскому краю, г. Чита, Российская Федерация

Введение: янтарь, не являясь по сути драгоценным камнем, имеет важное стратегическое значение, оказывая существенное влияние на формирование экономической политики государства в области регулирования оборота природных ресурсов. Именно поэтому янтарь входит в перечень стратегически важных 
ресурсов для целей ст. $226^{1}$ УК РФ и нередко является предметом контрабанды. Уникальные янтарные образования в предусмотренных федеральным законом случаях приравнены к драгоценным камням. Вместе с тем уголовно-правовая защита янтаря от незаконного оборота несовершенна, что обусловило цель статьи выработать рекомендации по усилению уголовно-правовой защиты янтаря и уникальных янтарных образований как стратегически важного ресурса. Методы: методологическую основу исследования составляет системный подход, а также совокупность методов научного познания, среди которых следует выделить методы анализа и синтеза, диалектический, логический, конкретно-социологический методы познания. Результаты: авторами выявлены противоречия в федеральном законодательстве, препятствующие полноценной уголовно-правовой охране янтаря как стратегически важного ресурса и в ряде случаев камня, приравненного к драгоценному. Кроме того, выявлены противоречия, касающиеся предмета регулирования ст. 191 УК РФ в целом. На основе криминологического анализа обоснована экономическая значимость янтаря и уникальных янтарных образований, а также необходимость его защиты от противоправных посягательств. Выводы: на основе анализа положений уголовного законодательства, а также Федерального закона «О драгоценных металлах и драгоценных камнях» авторами сформулированы предложения по совершенствованию нормы уголовного закона, предусматривающей ответственность за незаконный оборот драгоценных металлов, природных драгоценных камней или жемчуга.

Ключевые слова: янтарь, уникальные янтарные образования, драгоценные камни, жемчуг, стратегически важные ресурсы, экономическая безопасность.

Цитирование. Бархатова Е. Н., Беломестнов Н. Е. Янтарь - природное богатство вне уголовно-правовой защиты // Legal Concept = Правовая парадигма. -2019 . - T. 18, № 4. - C. 174-180. - DOI: https://doi.org/ 10.15688/lc.jvolsu.2019.4.24

\section{Введение}

Янтарь является уникальным природным образованием. Красота обработанного камня, его относительно невысокая стоимость, полезные свойства камня, обусловленные его химическим составом, - все это делает янтарь стратегически важным ресурсом для нашего государства. Уникальность янтаря заключается еще и в том, что большая часть его запасов находится в Российской Федерации (90\%). Это так называемый балтийский янтарь. Оставшиеся 10 \% приходятся на Украину и Республику Доминикана. Ежегодный объем добычи янтаря в России составляет примерно 300 т (по официальным данным, не включающим объемы добычи камня «черными копателями»). Единственным предприятием, официально осуществляющим добычу янтаря в России, является Калининградский янтарный комбинат. Часть добытого янтаря используется для изготовления ювелирных изделий, а также предметов быта, часть реализуется. Калиниградским янтарным комбинатом подписано долгосрочное соглашение о сотрудничестве с биржей «Санкт-Петербург». В результате сотрудничества в 2017 г. комбинатом реализован янтарь на сумму 1,2 млрд рублей [4, с. 119].
Что же касается незаконной добычи янтаря, то по данным МВД России ее объемы в среднем составляют 15 т в год оценочной стоимостью 1,3 млрд рублей. Ежегодно МВД России фиксирует около 1,5 тысяч административных правонарушений, совершенных в данной сфере физическими лицами по ст. 7.5 КоАП РФ [11].

По оценкам специалистов годовой доход от незаконной добычи янтаря колеблется от 800 тыс. руб. до 10 млн руб. в год [3].

Необходимость защиты янтаря подтверждается и озабоченностью данным вопросом Государственной думы Российской Федерации, принявшей в июле 2019 г. в первом чтении законопроект об установлении уголовной ответственности за самовольную добычу и незаконный оборот янтаря, нефрита или иных полудрагоценных камней.

Представляется, однако, что даже с принятием вышеуказанного закона не все вопросы в области правового регулирования оборота янтаря будут решены, чем и обусловлена необходимость изучения данной темы.

\section{Регулирование оборота янтаря на современном этапе}

Согласно Товарной номенклатуре внешнеэкономической деятельности Евразийского 
экономического союза (ТН ВЭД ЕАЭС) (ред. от 24.07.2018; т. IV, разд. XIV-XVI, гр. 7184) янтарь относится к полудрагоценным камням. В соответствии с постановлением Правительства Российской Федерации от 13 сентября 2012 г. № 923 (в ред. от 5 апреля 2019 г.) «Об утверждении перечня стратегически важных товаров и ресурсов для целей статьи $226^{1}$ Уголовного кодекса Российской Федерации, а также об определении видов стратегически важных товаров и ресурсов, для которых крупным размером признается стоимость, превышающая 100 тыс. рублей» янтарь отнесен к стратегически важным ресурсам, что позволяет привлекать лиц к уголовной ответственности по ст. $226^{1}$ УК РФ за его контрабанду, вместе с тем за пределами уголовного закона остается его оборот так называемыми черными копателями [6]. Незаконная добыча янтаря, а также его транспортировка или сбыт преследуются только по ст. 7.5 КоАП РФ «Самовольная добыча янтаря, нефрита или иных полудрагоценных камней», что, на наш взгляд, малоэффективно, учитывая стратегическую значимость для Российской Федерации данного минерала, а также его высокое качество, что подтверждается фактом отнесения балтийского янтаря к первому классу согласно классификации, основанной на архитектуре углеродного скелета макромолекулярной структуры смол [2, с. 18].

В настоящее время на законодательном уровне предпринята попытка ликвидировать обозначенный пробел. Предложено ввести в УК РФ статью об ответственности за незаконный оборот янтаря, нефрита и других полудрагоценных камней, которая сконструирована по принципу административной преюдиции и предполагает, что к уголовной ответственности будут привлекаться лица, лишь повторно нарушившие запрет и являющиеся на момент повторного нарушения подвергнутыми административному наказанию.

Проект федерального закона был внесен в Государственную думу Российской Федерации 1 марта 2019 г. (сопроводительное письмо № 1871п-П9). Однако это далеко не первая попытка законодателя обеспечить уголовно-правовую охрану полудрагоценных камней. Так, речь об установлении подобной ответственности шла еще в 2003 году. Обоснование необходи- мости внесения изменений было аналогичным: внушительные объемы незаконно добываемого янтаря, неэффективность административного законодательства в борьбе с подобными нарушениями. Указывалось, что в течение 2002 г. сотрудниками милиции Калининградской области организованы оперативно-профилактические мероприятия, в рамках которых проверке подверглись более 300 предприятий, сферой деятельности которых являлся оборот янтаря, выявлено 128 административных правонарушений, изъято из оборота более 35 т янтаря-сырца. На государственном унитарном предприятии «Калининградский янтарный комбинат» регулярно осуществлялось хищение сырья из карьеров, затем незаконно добытый янтарь нелегально вывозился в Польшу и Литву. Для российского рынка на тот момент объем контрабанды влек потери до 90 \% пригодных для использования в производстве камней. В денежном эквиваленте эти потери можно оценить примерно в 30 млн долларов. Объем добываемого янтаря соотносился с объемом выпускаемых комбинатом ювелирных изделий как $99: 1$.

Кроме того, в пояснительной записке к проекту указывалось, что добыча янтаря на янтарном комбинате снизилась с 800 т в 1995 г. до 130 т в 2000 году. При этом объем его ввоза в Польшу не только не сократился, но даже вырос. Если в 1996 г. он составил 51 т, то в 1997 г. - 189 т, в 1998 г. - 154 т, не менее 70$80 \%$ от которых составляла контрабанда [10]. Проектом предлагалось дополнить УК РФ ст. $192^{1}$ «Незаконная добыча янтаря». Однако проект закона так и не был одобрен.

Намного позже, в 2016 г., депутаты ГД РФ снова выступили с законотворческой инициативой в поддержку уголовно-правовой защиты янтаря. Предлагалось ввести в УК РФ ст. $171^{3}$ «Самовольная добыча полудрагоценных камней или янтаря». Состав предполагался как преюдициальный либо материальный. Часть первая рассматриваемой статьи устанавливала уголовную ответственность за незаконную добычу янтаря, хранение, перевозку с целью сбыта или сбыт. Однако обязательным условием уголовной ответственности являлся крупный размер ущерба или полученного в результате такой деятельности дохода либо специальный субъект - лицо, подвергнутое административному наказанию по 
ч. 2 ст. 7.5 КоАП РФ. Часть вторая предусматривала ответственность за указанное деяние, совершенное в особо крупном размере или сопряженное с извлечением дохода в особо крупном размере, а также совершенное организованной преступной группой [8].

Однако и этот проект не был одобрен Государственной думой РФ в связи с необходимостью доработки. Так, в Федеральном законе от 21 февраля 1992 г. № 2395-1《О недрах», в соответствии с которым осуществляется добыча янтаря и других полудрагоценных камней, отсутствует понятие «места промышленной разработки полезных ископаемых». Кроме того, в отзыве на законопроект указывалось, что одновременно в Государственную думу РФ поступил проект закона о внесении изменений в ст. 7.5 КоАП РФ, которую предлагалось изложить в новой редакции, установив в санкции статьи возможность конфискации орудия добычи и промысла и увеличив размеры административного штра$\phi а$ [5]. Руководствуясь прежде всего принципом гуманизма, законодатель принял изменения, предусмотренные вторым проектом. Первый же снова был отложен «в долгий ящик».

Современный проект федерального закона вобрал в себя рекомендации первых двух и был подготовлен с учетом предыдущих ошибок и современных реалий, однако, на наш взгляд, остался далек от совершенства. Разработчики проекта не предлагают отдельную статью, а считают достаточным изменить редакцию имеющейся в законе ст. 191, расширив ее содержание до пяти частей. В название самой статьи предлагается добавить слова «янтаря, нефрита или иных полудрагоценных камней». В первой части предусматривается ответственность за совершение сделки с заведомо самовольно добытым янтарем, нефритом или иными полудрагоценными камнями, а равно их незаконные хранение, перевозка или пересылка в любом виде, состоянии, за исключением ювелирных и бытовых изделий и лома таких изделий, лицом, подвергнутым административному наказанию по ст. 7.5 КоАП РФ. Вторая часть предусматривает ответственность за то же деяние, совершенное в крупном размере, третья - за совершенное организованной группой или группой лиц по предварительному сговору. Четвертая и пятая части посвя- щены драгоценным металлам, природным драгоценным камням и жемчугу, представляя собой по сути первую и вторую части ст. 191 УК РФ до изменений.

Кроме того, предложено изменить редакцию ст. 255 «Нарушение правил охраны и использования недр», дополнив ее частями второй и третьей о самовольной добыче янтаря и нефрита, а также иных полудрагоценных камней [9].

На первый взгляд, кажется нелогичным тот факт, что за самовольную добычу полудрагоценных камней теперь лицу грозит уголовная ответственность, а за самовольную добычу драгоценных камней - административная ответственность по ст. 19.14 КоАП РФ «Нарушение правил извлечения, производства, использования, обращения, получения, учета и хранения драгоценных металлов, жемчуга, драгоценных камней или изделий, их содержащих». Такое законодательное решение можно объяснить тем, что при самовольной добыче драгоценных камней лицо не избежит уголовной ответственности, поскольку не сдаст государству добытые камни, а соответственно, совершит преступление, предусмотренное ст. 192 УК РФ «Нарушение правил сдачи государству драгоценных металлов и драгоценных камней»), но только в том случае, если деяние совершено в крупном размере. В предлагаемой ч. 3 ст. 255 УК РФ также присутствует указание на крупный размер, однако в ч. 2 речь идет о совершении преступления лицом, подвергнутым административному наказанию, для которого, как следует из логики статьи, наличие крупного размера не обязательно. Таким образом нормы уголовного и административного законодательства, находясь в сложной взаимосвязи, позволяют обеспечить надлежащую охрану природных ресурсов.

Однако недостатком является по-прежнему оставленная без внимания основная норма, закрепленная в ст. 191 УК РФ в части указания предмета посягательства. Нами уже указывалось на тот факт, что норма в современной редакции находится в диссонансе с положениями Федерального закона от 26 марта 1998 г. № 41-Ф3 «О драгоценных металлах и драгоценных камнях», раскрывающего понятие драгоценного камня через перечисление тех минералов, которые относятся к чис- 


\section{ПРОТИВОДЕЙСТВИЕ ПРЕСТУПНОСТИ}

лу драгоценных, и жемчуг, обособленный законодателем в УК РФ, указанным федеральным законом включен в число драгоценных камней, в связи с чем его обособление в названии и диспозиции ст. 191 УК РФ представляется излишним [1, с. 46].

Вместе с тем в уголовном законе не нашли отражения уникальные янтарные образования, которые при определенных условиях могут быть приравнены к драгоценным камням. Данные условия перечислены в постановлении Правительства РФ от 5 января 1999 г. № 8 «Об утверждении порядка отнесения уникальных янтарных образований к драгоценным камням». Согласно постановлению для того, чтобы быть приравненным к драгоценному камню, янтарное образование должно быть уникальным, то есть обладать следующими признаками:

- масса более 1 кг,

- целостность не менее 80 \%, без трещин и сквозных раковин,

- хорошо сохранившиеся включения флоры и фауны размером более 10 мм [7].

Следуя логике законодателя, янтарные образования, приравненные к драгоценным камням, должны указываться в статье в качестве самостоятельного предмета. На данном этапе происходящих изменений можно возразить, что такая необходимость отсутствует ввиду установления уголовной ответственности за незаконный оборот янтаря в целом. Однако в предлагаемых частях 1-3 ст. 191 УК РФ речь идет о янтаре как о полудрагоценном камне, а уникальные янтарные образования имеют уже иной статус драгоценных камней. Из этого следуют квалификация по другой части статьи и более строгое наказание. Кроме того, представляется излишним указание в ст. 191 УК РФ на природное происхождение охраняемых нормой драгоценных камней, поскольку в соответствии с упомянутым выше Федеральным законом «О драгоценных металлах и драгоценных камнях» искусственно выращенные камни к драгоценным не относятся.

\section{Выводы}

С целью дальнейшего совершенствования положений, предложенных в законопроек- те об установлении уголовной ответственности за незаконный оборот и самовольную добычу янтаря, нефрита и других полудрагоценных камней, и устранения рассогласованности отдельных норм федерального законодательства, регулирующих оборот драгоценных металлов и драгоценных камней, предлагаем изложить название ст. 191 УК РФ в следующей редакции:

«Статья 191. Незаконный оборот драгоценных металлов, драгоценных камней, а также уникальных янтарных образований, приравненных к драгоценным камням, янтаря, нефрита или иных полудрагоценных камней».

Как можно заметить, из названия исключен такой предмет, как жемчуг, поскольку входит в понятие драгоценных камней, а также слово «природные», поскольку указание на то, что искусственно полученные камни не относятся к драгоценным, присутствует в федеральном законе, а потому подчеркивать данный факт излишне.

С учетом предложенного названия следует также скорректировать диспозицию статьи, указав в ней соответствующий предмет преступления. Предложенные законопроектом части 1-3 ст. 191 УК РФ целесообразно оставить в существующем виде, а в частях 4-5 исключить слова «природных» и «жемчуга» и дополнить словами «уникальных янтарных образований, приравненных к драгоценным камням».

\section{СПИСОК ЛИТЕРАТУРЫ}

1. Бархатова, Е. Н. Особенности законодательного регулирования ответственности за незаконный оборот драгоценных металлов и драгоценных камней / Е. Н. Бархатова // Вестник ВосточноСибирского институга МВД России. - 2019. - № 2. C. 44-51.

2. Верховская, Я. И. Исследование оптических свойств янтаря (сукцинита) методом инфракрасной спектроскопии / Я. И. Верховская, В. Т. Прокопенко, Н. П. Сапунова // Научно-технический вестник информационных технологий, механики и оптики. - 2018. Т. 18, № 1.-C. 15-23.

3. ГД приняла в I чтении закон об ответственности за незаконную добычу янтаря // РИА-новости. - Электрон. текстовые дан. - Режим доступа: 
https://ria.ru/20190716/1556580897.html (дата обращения: 23.07.2019). - Загл. с экрана.

4. Малашенков, Б. М. Янтарная отрасль Российской Федерации и мировой рынок янтаря / Б. М. Малашенков // Государственное управление. Электронный вестник. - 2018. - Вып. 69. C. $103-126$.

5. Николаев, Я. За незаконную добычу янтаря накажут лишением свободы // Рос. газета. 2016. - 4 окт. (№ 7091).

6. Об утверждении перечня стратегически важных товаров и ресурсов для целей статьи $226^{1}$ Уголовного кодекса Российской Федерации, а также об определении видов стратегически важных товаров и ресурсов, для которых крупным размером признается стоимость, превышающая 100 тыс. рублей : постановление Правительства Российской Федерации от 13 сентября 2012 г. № 923 (в ред. от 5 апреля 2019 г.) // Рос. газета. - 2012. - 21 сент. (№ 218).

7. Об утверждении порядка отнесения уникальных янтарных образований к драгоценным камням : постановление Правительства Российской Федерации от 5 янв. 1999 г. № 8 (в ред. от 16 дек. 2014 г.) // Рос. газета. - 1999. - 22 янв. (№ 12).

8. О внесении изменений в Уголовный кодекс Российской Федерации и Уголовно-процессуальный кодекс Российской Федерации (в части установления уголовной ответственности за самовольную добычу драгоценных металлов, природных драгоценных камней, жемчуга, полудрагоценных камней или янтаря) : проект федер. закона № 1186913-6 [не действует]. - Доступ из справ.-правовой системы «КонсультантПлюс».

9. О внесении изменений в Уголовный кодекс Российской Федерации и Уголовно-процессуальный кодекс Российской Федерации в части установления ответственности за самовольную добычу и незаконный оборот янтаря, нефрита или иных полудрагоценных камней : проект федер. закона № 657608-7 от 1 марта 2019 г. - Доступ из справ.правовой системы «Консультант Плюс».

10. Пояснительная записка к проекту федерального закона «О внесении дополнения в Уголовный кодекс Российской Федерации и Уголовнопроцессуальный кодекс Российской Федерации (об установлении уголовной ответственности за незаконную добычу янтаря)». - Электрон. текстовые дан. - Режим доступа: https://www.lawmix.ru/ law_project/8797 (дата обращения: 29.07.2019). - Загл. с экрана.

11. Статистические данные ЦСИ ГИАЦ МВД России // Главный информационно-аналитический центр МВД РФ. - Электрон. текстовые дан. - Режим доступа: https://мвд.pф/mvd/structure1/Centri/ Glavnij_informacionno_analiticheskij_cen.-Загл. c экрана.

\section{REFERENCES}

1. Barkhatova E.N. Osobennosti zakonodatelnogo regulirovaniya otvetstvennosti za nezakonnyy oborot dragotsennykh metallov i dragotsennykh kamney [Features of Legislative Regulation of Liability for the Illegal Circulation of Precious Metals and Precious Stones]. Vestnik Vostochno-Sibirskogo instituta MVD Rossii [Bulletin of the East Siberian Institute of the Ministry of Internal Affairs of Russia], 2019, no. 2, pp. 44-51.

2. Verkhovskaya Ya.I., Prokopenko V.T., Sapunova N.P. Issledovanie opticheskikh svoystv yantarya (suktsinita) metodom infrakrasnoy spektroskopii [Study of the Optical Properties of Amber (Succinite) by Infrared Spectroscopy]. Nauchno-tekhnicheskiy vestnik informatsionnykh tekhnologiy, mekhaniki i optiki [Scientific and Technical Journal of Information Technologies, Mechanics and Optics], 2018, no. 1, vol. 18, pp. 15-23.

3. GD prinyala $\mathrm{v} 1$ chtenii zakon ob otvetstvennosti za nezakonnuyu dobychu yantarya [The State Duma Adopted in I Reading a Law on Liability for the Illegal Mining of Amber]. RIA-novosti [Information RIA-news]. URL: https://ria.ru/20190716/ 1556580897.html (accessed 23 Jule 2019).

4. Malashenkov B.M. Yantarnaya otras1 Rossiyskoy Federatsii i mirovoy rynok yantarya [Amber Industry of the Russian Federation and the World Market of Amber]. Gosudarstvennoe upravlenie. Elektronnyy vestnik [State Administration. Electronic Messenger], 2018, vol. 69, pp. 103-126.

5. Nikolaev Ya. Za nezakonnuyu dobychu yantarya nakazhut lisheniem svobody [For Illegal Mining of Amber Will Be Punished with Imprisonment]. Ros. gazeta [Ros. newspaper], 2016, October $4^{\text {th }}$, no. 7091.

6. Ob utverzhdenii perechnya strategicheski vazhnykh tovarov i resursov dlya tseley stati $226^{1}$ Ugolovnogo kodeksa Rossiyskoy Federatsii, a takzhe ob opredelenii vidov strategicheski vazhnykh tovarov i resursov, dlya kotorykh krupnym razmerom priznaetsya stoimost, prevyshayushchaya 100 tys. rubley: postanovlenie Pravitelstva Rossiyskoy Federatsii ot 13 sentyabrya 2012 g. № 923 (v red. ot 5 aprelya 2019 g.) [On Approval of the List of Strategically Important Goods and Resources for the Purposes of Article $226^{1}$ of the Criminal Code of the Russian Federation, as Well as on the Definition of Types of Strategically Important Goods and Resources for Which the Value of More Than 100 Thousand Rubles is Recognized as a Large Amount. Decree of the Government of the Russian Federation of September 13, 2012. №. 923 (as amended on April 5, 2019)]. Ros. gazeta [Ros. Newspaper], 2012, September 21, no. 218. 


\section{ПРОТИВОДЕЙСТВИЕ ПРЕСТУПНОСТИ}

7. Ob utverzhdenii poryadka otneseniya unikalnykh yantarnykh obrazovaniy k dragotsennym kamnyam: postanovlenie Pravitelstva Rossiyskoy Federatsii ot 5 yanv. 1999 g. № 8 (v red. ot 16 dek. 2014 g.) [On Approval of the Procedure for Attributing Unique Amber Formations to Precious Stones: Decree of the Government of the Russian Federation dated January 5. 1999 № 8 (as amended on December 16, 2014)]. Ros. Gazeta [Ros. Newspaper], 1999, Jan. 22, no. 12.

8. O vnesenii izmeneniy $v$ Ugolovnyy kodeks Rossiyskoy Federatsii $i$ Ugolovno-protsessualnyy kodeks Rossiyskoy Federatsii (v chasti ustanovleniya ugolovnoy otvetstvennosti za samovolnuyu dobychu dragotsennykh metallov, prirodnykh dragotsennykh kamney, zhemchuga, poludragotsennykh kamney ili yantaria): proekt feder. zakona № 1186913-6 [ne deistvuet] [On Amendments to the Criminal Code of the Russian Federation and the Criminal Procedure Code of the Russian Federation (In Terms of Establishing Criminal Responsibility for the Unauthorized Mining of Precious Metals, Natural Gems, Pearls, Semi-Precious Stones or Amber): Draft Federal Law № 1186913-6 (not operational)]. Access from the Reference Legal System "ConsultantPlus".

9. O vnesenii izmeneniy $v$ Ugolovnyy kodeks Rossiyskoy Federatsii i Ugolovno-protsessualnyy kodeks Rossiyskoy Federatsii v chasti ustanovleniya otvetstvennosti za samovolnuyu dobychu $i$ nezakonnyy oborot yantarya, nefrita ili inykh poludragotsennykh kamney: proekt feder. zakona № 657608-7 ot 1 marta $2019 \mathrm{~g}$. [On Amendments to the Criminal Code of the Russian Federation and the Criminal Procedure Code of the Russian Federation in Terms of Establishing Liability for Unauthorized Mining and Trafficking of Amber, Jade or Other SemiPrecious Stones Reference Legal System: Draft Federal Law № 657608-7 of March 1, 2019]. Access from the Reference Legal System "ConsultantPlus".

10. Poyasnitelnaya zapiska k proektu federalnogo zakona «O vnesenii dopolneniya v Ugolovnyy kodeks Rossiyskoy Federatsii i Ugolovno-protsessualnyy kodeks Rossiyskoy Federatsii (ob ustanovlenii ugolovnoy otvetstvennosti za nezakonnuyu dobychu yantarya)» [Explanatory Note to the Draft Federal Law "On Amendments to the Criminal Code of the Russian Federation and the Criminal Procedure Code of the Russian Federation (On Establishing Criminal Liability for Illegal Extraction of Amber)"]. URL: https:// www.lawmix.ru/law project/8797 (accessed 29 Jule 2019).

11. Statisticheskie dannye TsSI GIATs MVD Rossii [Statistics of the SRC GIAC Ministry of Internal Affairs of Russia]. URL: https://мвд.pф/mvd/ structure1/Centri/Glavnij_informacionno_ analiticheskij_cen.

\section{Information about the Authors}

Ekaterina N. Barkhatova, Candidate of Sciences (Jurisprudence), Associate Professor, Department of Criminal Law and Criminology, East Siberian Institute of the Ministry of Internal Affairs of the Russian Federation, Lermontov St., 110, 664074 Irkutsk, Russian Federation, Solncevelvet@rambler.ru, https://orcid.org/0000-0002-0381-5462

Nikita E. Belomestnov, Criminal Intelligence Investigator, Department for Combating Organized Criminal Groups and Criminal Communities of the $6^{\text {th }}$ Department (for Combating Organized Crime of a General Criminal Orientation) of the Criminal Investigation Department, Department of the Ministry of the Internal Affairs of the Russian Federation for the Trans-Baikal Territory, P. Osipenko St., 21, 672089 Chita, Russian Federation, belomestnov.nik@yandex.ru, https://orcid.org/0000-0002-5715-9800

\section{Информация об авторах}

Екатерина Николаевна Бархатова, кандидат юридических наук, доцент кафедры уголовного права и криминологии, Восточно-Сибирский институт МВД России, ул. Лермонтова, 110, 664074 г. Иркутск, Российская Федерация, Solncevelvet@rambler.ru, https://orcid.org/0000-0002-0381-5462

Никита Евгеньевич Беломестнов, оперуполномоченный, отделение по борьбе с организованными преступными группами и преступными сообществами, 6-й отдел (по борьбе с организованной преступностью общеуголовной направленности) управления уголовного розыска, Управление Министерства внутренних дел Российской Федерации по Забайкальскому краю, ул. П. Осипенко, 21, 672089 г. Чита, Российская Федерация, belomestnov.nik@yandex.ru, https://orcid.org/0000-0002-5715-9800 